\title{
OECONOMIA
}

COPERNICANA

\section{VOLUME 11 ISSUE 2 JUNE 2020}

p-ISSN 2083-1277, e-ISSN 2353-1827

www.oeconomia.pl

\section{ORIGINAL ARTICLE}

Citation: Vrbka, J. (2020). The use of neural networks to determine value based drivers for SMEs operating in the rural areas of the Czech Republic. Oeconomia Copernicana, 11(2), 325346. doi: $10.24136 /$ oc. 2020.014

Contact: vrbka@mail.vstecb.cz; Institute of Technology and Business in Ceske Budejovice, School of Expertness and Valuation, Okruzni 517/10, 37001 Ceske Budejovice, Czech Republic

Received: 23.02.2020; Revised: 29.04.2020; Accepted: 15.05.2020; Published online: 25.06.2020

\author{
Jaromír Vrbka \\ School of Expertness and Valuation, Czech Republic \\ (iD) orcid.org/0000-0002-6356-4810
}

\section{The use of neural networks to determine value based drivers for SMEs operating in the rural areas of the Czech Republic}

\author{
JEL Classification: $C 45 ; G 32$
}

Keywords: business value drivers; value based drivers; small and medium-sized enterprises; rural area; ultimate goal, economic value added; neural networks

\begin{abstract}
Research background: In the past, the main objective of a company was to generate sufficient profit. Nowadays, a company must seek to achieve much broader objectives. To be successful in this pursuit, it must not only measure financial performance, but also monitor internal and external developments, increase shareholders' wealth and protect the interests of other stakeholders, i.e. to analyze and act on those factors that affect company value.

Purpose of the article: The objective of the contribution is to determine through the use of artificial neural networks the relationship between business value drivers, or value based drivers (VBD), and EVA Equity, which is economic value added (EVA), of small and medium-sized enterprises operating in the rural areas of the Czech Republic.

Methods: The data was obtained from the Bisnode's Albertina database. The data set consists of the profit and loss accounts for 2013 to 2017 of small and medium-sized enterprises operating in rural areas of the Czech Republic. Two scenarios are analyzed. In the first, the independent variables are only the value drivers, whereas in the second, company location (region) is included. The objective is to find the dependence of EVA Equity on individual VBD and company location. A sensitivity analysis is conducted, on the basis of which the importance of individual value drivers and company location is determined.

Findings \& Value added: The output is a set of value drivers, which could be used by company managers to regulate the growth of EVA Equity, i.e. value for shareholders. The findings reveal that the difference between successful and unsuccessful companies is determined by the level of
\end{abstract}


involvement of human capital; companies use a large number of substitutes for factors of production, whereby the involvement of borrowed capital is likely to cause a positive financial leverage effect.

\section{Introduction}

Performance measures not only provide useful qualitative information about the processes within a company and the products and services it produces or supplies, but also provide tools with which to understand, manage and improve a company's activities and performance. According to Delgado Ferraz and Gallaro-Vázquez (2016), for a company to be successful, it must, in addition to the monitoring of internal and external developments, also measure performance and determine its value.

In the past, the main objective of a company was to generate sufficient profit. Nowadays, a company must seek to achieve much broader objectives, namely to increase company value and maximize shareholder wealth. Within this context, recent studies have shown that all key decisions made by a company should be taken with the aim of increasing company value (Hall, 2016; Vidgen et al., 2017; Machová \& Rowland, 2018; Stehel et al., 2019). Unfortunately, it would appear that many companies have problems understanding the substance of this matter and do not monitor or measure company value at all. This problem is even more pronounced in small and medium-sized enterprises (SMEs), in particular in those based in rural areas. Changes in company value are reflected in both the levels of wealth creation for shareholders and the promotion of the interests of other stakeholders. Identifying and understanding the factors that affect company value is, therefore, essential. However, this process depends on a wide range of factors, such as a company's market position, demand for its products, innovative capacity, effective cost management, ability to seize investment opportunities, and the effective use of available resources (Stehel \& Vochozka, 2016). On the basis of previous research conducted by the author (e.g. Machová \& Vrbka, 2018), it can be stated that company value is affected by all of the following: materials consumption, costs of goods sold, services, personnel costs, depreciation of fixed intangible and tangible assets, and interest payable. For this contribution, the factors of production represented by the aforementioned will, therefore, be considered as value drivers.

Simply put, value drivers are those variables that significantly affect the evaluation of a company's value. In practice, the identification of these variables is achieved either through strategic analysis of a company, benchmarking or the decomposition of economic value added (EVA). 
Within this context, the EVA indicator appears to be the most accurate, because it takes into account the degree of investment risk (Vochozka \& Machová, 2017; Machová \& Rowland, 2018). It is for this reason that it is used in this contribution. However, this contribution does not only aim to identify the value drivers of companies based in rural areas through the decomposition of this indicator, but also through an innovative approach based on a combination of EVA and artificial neural networks for decisionmaking. The application of artificial neural networks comes with a number of advantages, namely that they are able to learn, to capture strong nonlinear dependencies, to work with large amounts of data, and to deliver better results than the application of other well-established methods (Vochozka et al., 2019).

The objective of this contribution is therefore to determine through the use of artificial neural networks the relationship between business value drivers, or value based drivers (VBD), and the equity, or economic value added (EVA), of small and medium-sized enterprises operating in the rural areas of the Czech Republic.

On the basis of this objective, several partial objectives were set:

1. To determine the relationship by means of a model that represents the production function, whereby the most important indicator is EVA Equity, not profit.

2. To conduct a sensitivity analysis to determine the influence each value driver has on the resulting EVA Equity.

In order to achieve the (partial) objective(s), the following research questions were formulated:

1. Do VBD directly affect EVA Equity?

2. Does company location affect the relationship between VBD and EVA Equity?

In the section on the theoretical background, the author adds more detailed information about the use of EVA, their points of view on the identification of value drivers, and describes the importance and specificities of rural-based companies. Studies are also presented in which neural networks were used for the identification of value drivers. In the section on methodology, the author describes the data obtained from the Bisnode's Albertina database and presents the procedure used in the application part (data processing, calculation of EVA Equity, calculation and identification of value drivers using Tibco's Statistica software). The author also describes the results of two scenarios. In the first one, the independent variables are only the VBD, whereas in the second one, company location (region) is included. The objective is to find the dependence of EVA Equity on individual VBD and company location. In the discussion section, the results are com- 
pared to previous research of the same kind. The contribution closes with conclusions and a statement on whether the (partial) objective(s) have been met, or not as the case may be.

\section{Literature review}

The ultimate goal of a business at the maturity stage of its lifecycle is considered to be growth of its value for shareholders. This can be measured, for example, in terms of free cash flows for shareholders (i.e. cash flows that can be withdrawn from the company without negatively affecting its operations) or economic value added for shareholders (EVA Equity), which measures the rate of appreciation of the owners' investment at a given level of risk (Klieštik et al., 2014; Machová \& Horák, 2020).

EVA Equity is calculated from the owners' perspective and is the relationship represented by the product of the difference in return on equity, alternative costs of equity and equity (Vochozka \& Rowland, 2015). The relationship between the ultimate goal and factors of production, i.e. the variables capable of generating the value, the so-called value based drivers (VBD), is not so clear. In professional literature, the term "value based drivers" was first used in the USA in relation to the concept of shareholder value. Firk et al. (2013) state that this term represents a set of company oriented economic indicators that together determine the value of a business.

The issue of VBD has been and is the focus of much research (Vochozka \& Machová, 2018). Hall (2016) identified which variables create company value according to categories and industries. Kuzey et al. (2014) conducted similar research focused on the influence of financial indicators on the value of a multinational company. Vidgen et al. (2017) identified the key sectors of business that need to be targeted in order to achieve optimal company value. Panaretou (2014) assessed the influence of business activities on company value in terms of risk management.

The impact of VBD should also be measured by small and mediumsized enterprises. According to Sulistyowati et al. (2018), the development of such companies forms the backbone of a populistic economic system, one that can help reduce poverty. They do so by helping a country or region expand its economic base, thereby contributing to an increase in value added. Likewise, they are important for creating job opportunities in rural areas.

Small rural businesses contribute significantly to the budgets of their communities, which in turn enables local governments to expand their ca- 
pability to support sustainable regional and rural development. By combining scarce private capital with public resources and dividing the risk, rural businesses are able to implement a relatively broad investment programme covering areas such as infrastructure development, eco-tourism and nature protection. Establishing small and medium-sized enterprises in rural areas enhances the potential of rural regions and increases their resilience to changes in production, market failure and economic cycles (Miao, 2010). Despite the importance and the positive impact of rural businesses, the obstacles in the way of their growth should not be forgotten. The most critical of these obstacles are those related to financial support and the creation of a healthy environment in which to prosper. The growing importance of micro-companies for the development of economic systems is reflected in the increase in employment rate and its positive impact on regional development, improvements in knowledge and qualifications, the expanding exchange of information, the creation of initiatives and the growing emphasis being placed on innovation (Serefoglu \& Gokkaya, 2018).

The competitive advantage small and medium-sized enterprises enjoy through their specialization means they play an important role in sustainable rural development (Brata et al., 2015). Support for such companies should be particularly strong in traditional agricultural regions, typically characterized by high unemployment rates, where there is an opportunity for them to create many job opportunities and employ workers to perform simple tasks at relatively low cost. The setting up of micro-companies in rural areas is closely related to the creation of new job opportunities (Hammann et al., 2009). In this way, it is possible to reduce the unemployment rate and create a new class of small business owners, thereby leading to improvements in the socio-economic circumstances and professional structure of these regions. By increasing the levels of employment in rural areas, micro-companies can alleviate social tensions and contribute to reducing the high social costs of transition (Janda, 2013). Strielkowski et al. (2015) focus on the characteristics of Polish micro-companies, especially the factors that influence their success. They conclude that rural-based micro-companies play a key role in sustainable rural development and the transformation of local economies by creating job opportunities, contributing to local budgets and protecting the environment.

In this contribution, artificial neural networks are used to identify the VBD of small and medium-sized enterprises. It is therefore necessary to draw attention to some outputs from the application of such neural networks in relation to VBD. For example, Di Tollo et al. (2012) used neural networks to analyse the relationship between value creation and innovativeness in technologically driven companies. They concluded that there 
was a strong dependency between the two. By means of cluster analysis through neural networks, the authors also identified those companies that generate the most value on this basis. Liu and Yeh (2016) developed a new model for value creation based on the application of neural networks. They highlight the importance of using specially adapted models for given industries within a national economy to determine company value. They conclude that by not doing so, the results can be significantly overstated. Wilimovska and Krzysztoszek (2013) put forward a method for predicting VBD based on artificial neural networks. They conducted a simulation of the model using the company Hama-Bis as their example. They identified factors that should be taken into consideration when valuing a company and the method for predicting value drivers. However, the research only included 22 large companies in Poland, which cannot be seen as a representative sample. Miles and Van Clieaf (2017) presented a complex model that leads to increased company value through organizational capital. The authors based their work on soft research - the strategy and proposals for the optimal distribution of resources within a company. They argue that a company only generates value if the role of strategic leadership creates the critical requirements needed for strategic adjustments in order to create a competitive business and economic model, whereby the structure of responsibility is aligned with the required level of innovations supported by corporate systems and processes.

\section{Research methodology}

The data source was Bisnode's Albertina database. The data set consisted of the profit and loss accounts for 2013 to 2017 of small and medium-sized enterprises operating in the rural areas of the Czech Republic. A rural area is defined as a municipality with a maximum of 25,000 inhabitants (Heckman et al., 1998). The companies represented the whole range of activities in the CZ-NACE industrial classification. The generated data set consisted of 193,122 data rows, with each row containing data on:

1. Company identification: company name, company registration number, municipality, region, size of municipality.

2. Company information: NACE classification, number of employees, year of financial statements.

3. Selected financial statements: balance sheet, profit and loss account.

The data set was processed and modified in MS Office Excel. In the table: "0" was entered in empty fields; an "EBIT" column was added; columns with zero variance were removed, as were those columns that con- 
tained zero entries, rows that appeared multiple times, and rows (entities) containing data for a period other than 12 months (different accounting periods); ROA (EBIT/Assets) and ROE (EAT/Equity) were calculated. All the necessary components for the calculation of EVA Equity (Neumaierová $\&$ Neumaier, 2008) from the shareholders' perspective, not from the company's point of view, were calculated: risk-free yield $-r_{f}$ (interest rate on 10 -year government bonds for the relevant year as of 31 December), indicators characterizing company size $-r_{L A}$, indicators characterizing production strength - rentrepreneurship, $X P$, indicators characterizing the relationship between assets and liabilities $-r_{\text {finstab }}$, weighted average costs of capital - WACC (risk-free yield + indicators characterizing company size + indicators characterizing the relationship between assets and liabilities):

$$
W A C C=r_{f}+r_{L A}+r_{\text {entrepreneurship }}+r_{\text {Finstab }}
$$

and alternative costs of equity $-r_{e}$ :

$$
r_{e}=\frac{W A C C * \frac{U Z}{A}-(1-d) * \frac{U}{B U+O} *\left(\frac{U Z}{A} * \frac{V K}{A}\right)}{\frac{V K}{A}}
$$

where:

$U Z$ - paid resources (equity and interest-bearing borrowed capital),

$A$ - assets,

$V K$ - Equity,

$B U-$ bank loans,

$O$ - bonds,

$\frac{U}{B U+o}-$ interest rate (also possible to use $i$ (interest)),

$d$ - tax rate (also possible to use $t(\operatorname{tax})$ ).

Paid resources - UZ (equity + issued long-term bonds + issued shortterm bonds + bank loans and overdrafts), corporate income tax rate $-d$ (by relevant year - tax rate has been $19 \%$ since 2010).

The EVA Equity indicator was calculated according to Neumaierová and Neumaier (2008):

$$
\text { EVA Equity }=\left(R O E-r_{e}\right) * V K
$$

The data was subsequently cleaned of extreme and nonsensical values, whereby EVA Equity entries that were not numbers were removed. The companies that met all the following conditions were kept in the data set: 
companies with positive assets, positive fixed assets, positive fixed financial assets, positive fixed intangible assets, positive circulating assets, positive stock, positive long-term receivables, positive short-term receivables, positive trade receivables, positive claims on associated companies, positive registered capital, positive reserve funds, positive reserves, positive cash, positive sales of goods, positive consumed materials, positive production consumption, positive performance, positive goods costs, positive depreciation, positive sales of fixed assets, positive sales of materials, positive net book value of sold fixed assets, positive cost interest, wage costs higher than CZK 120,000 per year, ROA (at the interval $-100 \%,+100 \%$ ), ROE (at the interval $-100 \%,+100 \%$ ), alternative costs of equity (at the interval $0 \%$, $+100 \%$ ), sales of goods and performance of at least CZK 120,000 per year. After applying the aforementioned conditions to the data set, the table consisted of 42,592 rows. The calculation of VBD was carried out using Tibco's Statistica software, version 13. The "data mining, neural networks, regression analysis" module was used for this purpose. The calculations were applied to two case scenarios. In the first, the independent variables were only the value drivers, whereas in the second, company location (region) was included. The objective was to find the dependence of EVA Equity on individual VBD and company location. A sensitivity analysis was conducted on the basis of which the importance of individual value drivers and company location was determined. The expectation was that this would produce a set of value drivers that could be used by company managers to regulate the growth of EVA Equity, i.e. value for shareholders. The procedure was as follows:

1. The data set was imported (42,592 rows).

2. The "data mining, neural networks, regression analysis" module was selected from the dialogue box.

3. The following variables were selected: continuous target variables, continuous predictors and categorical predictors.

4. The calculations were carried out for two scenarios:

a. Scenario 1:

i. Continuous target variable:

1. EVA

ii. Continuous predictors:

2. Materials consumption

3. Costs of goods sold

4. Services

5. Personnel costs

6. Depreciation of fixed intangible and tangible assets

7. Interest payables 
b. Scenario 2:

i. Continuous target variable:

1. EVA

ii. Continuous predictors:

2. Materials consumption

3. Costs of goods sold

4. Services

5. Personnel costs

6. Depreciation of fixed intangible and tangible assets

7. Interest payables

iii. Categorical predictors:

8. Company location

5. Under "Sampling", VNS and ANS were set. The ratio was set as follows: Training $-70 \%$, testing $-15 \%$ and validation $-15 \%$. The random selection seed was the default setting, with a value of 1,000 . In "Undersampling", the setting was also the default setting (undersampling would be random).

6. A new tab "SANS - Automated creation of networks" appeared. In "Basis", the minimum and maximum number of hidden neurons were entered for "MLP" networks (3 and 15 neurons, respectively) and "RBF" networks (21 and 30 neurons, respectively). The number of trainings was set at 10,000 and the number of retained networks to 5. As an error function, the least squares method was applied. As a result, only those neural networks were retained whose sum of residual squares in relation to the actual development were as low as possible, i.e. ideally 0 . Under the "MLP activation function", the following activation functions were selected: Identity, Logistic, Tanh, Exponential and Sine. Under "Weight decomposition" and "Initialization" the default settings were retained. "Training" was subsequently selected.

7. After some time, during which the neural networks are trained, the results appeared ("SANS - Results"), showing the 5 best retained neural networks. Under "Prediction", we selected "Output (target)", "Output", "Residuals", "Standard residuals", "Absolute residuals" and "Square residuals". In the bottom right, we subsequently selected "Training", "Testing" and "Validation". This revealed the retained neural networks, including their weights and architecture. A table of predictions and residuals for the individual networks (the difference between the actual situation and the prediction; in ideal circumstances, the sum should be zero) was then generated. This table included the statistics for the input data, i.e. the original data set divided into training, testing and validation 
data sets (minimum, maximum, average, deviation). A global sensitivity analysis was subsequently conducted.

After the calculation:

1. The relationship between VBD and EVA Equity in the form of a modified production function (see Table: Overview of active networks) was determined. The output, i.e. the best neural network, was stored in the form of a report "Weights", or alternatively in xml or C++.

2. The relationship between individual VBD and EVA Equity was determined (see Table: Sensitivity analysis).

3. The impact of the variable "region" (company location) on VBD was determined (see Table: Sensitivity analysis).

\section{Results}

\section{$V B D$ and EVA Equity}

Table 1 provides an overview of the active networks, i.e. those neural networks that were trained and retained. These are effectively the neural networks with the best characteristics in terms of the ratio between network performance and errors in relation to the individual data sets.

Although the performance of the models obtained in the form of neural networks was not very high, they are capable of describing the relationship between the factors of production, i.e. the value drivers and EVA Equity. Under ideal circumstances, the best model among the retained neural networks is the one with the highest performance for the whole data set, with similar performances for the individual data sets. On the basis of the results, the most interesting model therefore appears to be 2.MLP 6-8-1 (performance for training data set $>0.56$, testing data set $\sim 0.4$, validation data set > 0.44). The neural network was trained using the Quasi-Newton 83 algorithm and the logistic function used for the activation of both the hidden and output layer of neurons. The logistic function is able to capture the extreme values of the data set. The second most successful neural network appears to be 5.MLP 6-6-1, which was trained using the Quasi-Newton 92 algorithm. In this case, the hidden layer of neurons was activated using the hyperbolic tangent function and the output layer of neurons using the logistic function. To provide more information about the data included in the calculation, statistics on the data set were also presented.

The neural network model would work better if it was possible to identify the same statistics in all three data sets. However, it is evident that the applied random sampling divided the data into three uneven sets. For ex- 
ample, in the case of maximum costs of goods sold, the maximum in the training data set is more than four times higher than the maximum in the testing data set and more than five times higher than the maximum in the validation data set. Such differences explain the contrast in network performance across the individual data sets.

The results of the models calculated on the basis of the data set on which the neural networks were created, were presented. In this case, those networks are sought for which the calculated results are as close as possible to the values of the original data set in all three subsets. At the same time, it is necessary to examine the residuals, whose values should be as low as possible. Although, the standard residuals for the individual data sets are approximately at the same level, they are closest to the actual values of EVA Equity under network 5.MLP 6-6-1. In other words, of all the retained neural networks presented in Table 1, the performance of network 5.MLP 6-6-1 best describes the actual situation, with network 2.MLP 6-8-1 being the second most successful to do so.

Table 2 shows the sensitivity of EVA Equity to individual value drivers.

The main focus here is on the most successful model (even though the remaining neural networks show almost the same results). According to 5.MLP 6-6-1, the most important VBD is human labour. However, no distinction is made between managerial or operational work. The second most important VBD is services, which are seen as substitutes for human labour and machine work (which is normally valued on the basis of fixed asset (FA) depreciation). These two VBD are closely followed by costs of goods sold, which represents the business activities of the examined SMEs, interest payable, which represents the price of utilising borrowed capital, materials and energy consumption, and last but not least, FA depreciation. However, it would be a mistake to consider the position of FA depreciation as evidence that using fixed assets is not important for achieving a company's objectives. On the contrary, it could be stated that the use of all factors of production is important for companies. In this case, the comparison is relative because the model compares successful with less successful companies.

\section{VBD, EVA Equity and company location}

When examining the impact of company location on the VBD, the process is similar. The only difference is the involvement of the variable "Region", which identifies the location where the selected company is based and pays income tax. In general, it cannot be said with certainty that a company necessarily conducts business in the place where it is located. 
However, as the data set only examines SMEs, it can reasonably be assumed that a large volume of their activities is carried out in the place where they are located, especially if the location is understood to be a region in the Czech Republic. Table 3 shows the retained neural networks.

The influence of the new variable on the structure of the neural networks is clear. There are 19 neurons identified in the structure compared to the previous six, i.e. the original 6 factors of production complemented by the 13 regions of the Czech Republic. The SMEs in the data set do not include companies located in Prague. Although Prague is defined as a region, none of its parts corresponds to the definition of a rural area.

Close examination shows that the 3.MLP 19-12-1 network is the most successful, although its performance is not high (performance for training data set $>0.53$, testing data set $>0.32$, validation data set $>0.41$ ). The neural network was created by Quasi-Newton 93 algorithm calculation. Both the hidden and output layers of neurons were activated using the logistic function.

For the second scenario, as in the first, the data were divided into training, testing and validation data sets. The predicted data were also presented. As stated above, we are looking for the neural network with ideally the same characteristics as the actual situation. Likewise, there is also a focus on residuals, with the differences between them once again proving to be minimal. The values presented in Table 3 reveal that the network closest to the actual situation is 3.MLP 19-12-1. A sensitivity analysis was also conducted in this case (see Table 4).

The table clearly shows that interest payable has the biggest influence on EVA Equity. This is followed by personnel costs, costs of goods sold, company location, services, materials and energy consumption and FA depreciation, respectively. A comparison of the results of the two most successful neural networks is presented in Table 5 .

The table clearly shows a big difference between the two, with network 5.MLP 6-8-1 showing a significantly better performance across all data sets. It also produces the smallest margin of error (4.1-6.6\%).

Figure 1 is a scatter plot, which illustrates actual EVA Equity, EVA Equity according to 5.MLP 6-8-1, and EVA Equity according to 3.MLP 1912-1 for personnel costs.

Under ideal circumstances, the individual dots for the 5.MLP 6-8-1 and 3.MLP 19-12-1 networks should correspond with the dots for the actual EVA Equity. If there is a discrepancy, this is seen as an error in the relevant model. On this basis, it is therefore possible to answer both research questions: 
1. Both scenarios, and in particular the first, proved that EVA Equity is dependent on factors of production, i.e. value based drivers.

2. The influence of company location is negligible. The performance of the obtained neural networks is significantly lower if company location is applied as a variable. It is, therefore, possible to state that company location does not have any influence on the value and importance of value based drivers.

\section{Discussion}

This contribution is primarily focused on determining the relationship between VBD and the EVA Equity of SMEs operating in rural areas of the Czech Republic. In general, the majority of research on this topic is based on the assumption that the identification of VBD is essential for a company (e.g. Cheverton, 2004; Andrea et al., 2015). However, these studies differ in their definitions of VBD and the tools and methods used for their identification. They also differ in terms of the data used and the individual items in which VBD are sought, including qualitative and quantitative information. For example, Akalu (2002) identified qualitative VBD. These include net profit, interest costs, income tax, fixed investment costs and investment in working capital. Lin and Tang (2008) did the same for the high-tech industry in Taiwan. Their qualitative VBD include innovations and technologies, employees, goodwill and relationships with stakeholders. According to Reno and Vadi (2010), VBD in Estonian industrial companies refers to human relations, open organization, defined objectives and internal processes. The submitted contribution uses the factors of production as they are quantitatively defined by the items in the financial statements of the selected companies in the data set. However, they can also be defined qualitatively. Some authors prefer to focus on the identification of VBD within a company, whereas others outside a company. According to Koller et al. (2005) and Olsen (2008), internal VBD include, among other things, free cash flows, return on capital employed, customer service and economic profit, and external VBD include macroeconomic indicators. Other authors categorize VBD into certain groups. Rappaport (1998) introduced the first model describing the relationship between VBD and corporate objectives. He categorized VBD into three groups: investment, operative and financial. Scarlet (2001) added another group - intangible. Most studies also agree that VBD are different for every industry within a national economy (e.g. Panaretou, 2014; Hall, 2016). 
In the first scenario, the most important factor for SMEs in rural areas was found to be human labour, followed by services, which are seen as substitutes for human labour and machine work (which is normally valued on the basis of fixed asset (FA) depreciation), and the costs of goods sold, which represents the business activities of the examined SMEs. In the second scenario, the value of an enterprise is mostly affected by interest payable, followed by personnel costs and the costs of goods sold. The results can be interpreted as follows: the difference between successful and unsuccessful companies is dependent on the degree of involvement of human capital, as well as borrowed capital, which causes a positive financial leverage effect. It is in this assessment that partial parallels can be found with other studies. For example, Kuzey et al. (2014) identified the significant impact the financial leverage effect has on company value. However, it should be noted that only a small number of studies have focused on the identification of VBD through the application of artificial intelligence, e. g. the aforementioned studies by Di Tollo et al. (2012), Liu and Yeh (2016), Wilimovska and Krzysztoszek (2013) and Miles and Van Clieaf (2017). Most of the referenced studies in this part of the contribution used other methods for the identification of VBD. The information obtained indicates that none of the authors conducted research similar to the research carried out for the purposes of this contribution. This can be considered the main benefit of the submitted contribution, which is innovative in its field.

From the above, it follows that, in practice, the identification of VBD is a very subjective matter, which is a limitation of this contribution. For the reasons described, VBD are only sought in the area of factors of production. Kazlauskiene and Christauskas (2008) argue that a company itself should identify the VBD that are significant to it, a conclusion that the author of this contribution agrees with. The submitted contribution only focuses on SMEs operating in rural areas. The objective was not to identify VBD for a specific company (although this would produce the most accurate set of VBD), but rather to present a suitable combination of methods that would provide a guideline for businesses to identify VBD. The author believes that VBD are related to factors of production, which represent the main activities of every company, and that it is very important for a company to utilise all of them. However, in this case, the comparison is relative because the created models compare successful with less successful companies. If, within this context, a specific business entity is able to identify its most important factor(s) of production, it can therefore also manage its value. It goes without saying that value management is not only an issue of identifying VBD, but also about the decomposition and incorporation 
thereof in the tactical and operational plans of a company. This, however, is not addressed in the contribution.

\section{Conclusions}

The objective of the contribution was to determine the relationship between VBD and the EVA Equity of SMEs operating in the rural areas of the Czech Republic. Based on the main objective, the following partial objectives were set:

1. To determine the relationship by means of a model that represents the production function, whereby the most important indicator is EVA Equity, not profit.

2. To conduct a sensitivity analysis to determine the influence each value driver has on the resulting EVA Equity.

For the purposes of the contribution, ten models representing the relationship between VBD and EVA Equity were chosen. The first set of five neural networks only concerned the relationship between VBD and the ultimate objective of a company. The second set of five neural networks included a categorical variable, namely "region" (company location), in the calculation.

Sensitivity analyses were conducted for all the models. The results of the most successful neural networks can be interpreted as follows:

1. All the selected companies were approximately at the same technological level.

2. The difference between successful and unsuccessful companies depends on the level of involvement of human capital, which determines the efficiency of the use of all VBD.

3. The selected companies are engaged both in production and trade (i.e. they convert inputs into outputs and purchase goods for resale).

4. The selected companies use a large number of substitutes for factors of production, probably performance of work.

5. Borrowed capital is likely to create a positive financial leverage effect. This interpretation provides a basis for several recommendations for the managements/owners of companies:

1. To pay greater attention to human resources management: Workers generate a competitive advantage in the market.

2. To give consideration to the replacement of part of the workforce with substitutes: In this case, substitutes refers to agency workers.

3. To give greater consideration to the utilisation of borrowed capital: Financial leverage has a positive effect. 
As the achieved results of the research do not appear to be logical, further research will involve a more detailed analysis of company location and its influence on the creation of company value (i.e. EVA Equity). The selection and subjectivity of the research sample for the identification of VBD was identified as a limitation of this contribution. This was addressed in detail in the Discussion.

The contribution focused on determining the relationship between VBD and the EVA Equity of SMEs operating in rural areas of the Czech Republic, which resulted in clear recommendations for companies to pay greater attention to human resources management, replacement of the workforce with substitutes, and the greater utilisation of borrowed capital. In addition, the results can be applied to SMEs operating in rural areas of other countries and the methodology standardized and applied in the international context.

\section{References}

Akalu, M. M. (2002). Measuring and ranking value drivers. Retrieved from https://www.econstor.eu/bitstream/10419/85955/1/02043.pdf (20.01.2020).

Andrea, B., Coulson, A., Hogan, R., \& Evans, J. D. (2015). Does the strategic alignment of value drivers impact earnings persistence? Sustainability Accounting, Management and Policy Journal, 6(3). doi: 10.1108/SAMPJ-11-20140073.

Brata, H. O., Estensen, L., \& Ekambaram, A. (2015). Competence brokering: an efficient tool to provide R\&D to SMEs in rural areas. In M. Massaro \& A. Garlatti (Eds.). Proceedings of the European conference on knowledge management. Reading: Academic Conferences and Publishing International Limited.

Delgado Ferraz, F. A., \& Gallardo-Vázquez, D. (2016). Measurement tool to assess the relationship between corporate social responsibility, training practices and business performance. Journal of Cleaner Production, 129. doi: 10.1016/j.jcle pro.2016.03.104.

Di Tollo, G., Tanev, S., Davide, D. M., \& Ma, Z. (2012). Neural networks to model the innovativeness perception of co-creative firms. Expert Systems with Application, 39(16). doi: 10.1016/j.eswa.2012.05.022.

Firk, S., Schrapp, S., \& Wolff, M. (2013). Drivers of value creation - the role of value-based management and underlying institutions. Management Accounting Research, 33. doi: 10.1016/j.mar.2016.04.002.

Hall, J. H. (2016). Industry-specific determinants of shareholder value creation. Studies in Economics and Finance, 33(2). doi: 10.1108/SEF-08-2014-0155.

Hall, J. H. (2016). Industry-specific determinants of shareholder value creation. Studies in Economics and Finance, 33(2). doi: 10.1108/SEF-08-2014-0155. 
Hammann, E. M., Habisch, A., \& Pechlaner, H. (2008). Values that create value: socially responsible business practices in SMEs - empirical evidence from German companies. Business Ethics: A European Review, 18(1). doi: 10.1111/ j.1467-8608.2009.01547.x.

Heckman, T. G., Somlai, A. M., Otto-Salaj, L., \& Davantes, B. R. (1998). Healthrelated quality of life among people living with HIV disease in small communities and rural areas. Psychology \& Health, 13(5). doi: 10.1080/08870449 808407436

Cheverton, P. (2004). Key marketing skills: strategies, tools \& techniquies for marketing success. London: Kogan Page.

Janda, K., Rausser, G., \& Strielkowski, W. (2013). Determinants of profitability of Polish rural micro-enterprises at the time of EU accession. Eastern European Countryside, 19(1). doi: 10.2478/eec-2013-0009.

Kazlauskiene, V., \& Christauskas, C. (2008). Business valuation model based on the analysis of business value drivers. Inzinerine Ekonomika-Engineering Economics, 2.

Klieštik, T., Lyakin, A. N., \& Valášková, K. (2014). Stochastic calculus and modelling in economics and finance. In G. Lee (Ed.). 2nd international conference on economics and social science, information engineering research institute, advances in education research. Texas City: Information Engineering Research Institute.

Koller, T., Copeland, T. E., Goedhart, M., \& Wessels, D. (2005). Valuation: measuring and managing the value of companies. New York: John Wiley \& Sons.

Kuzey, C., Uyar, A., \& Delen, D. (2014). The impact of multinationality on firm value: a comparative analysis of machine learning techniques. Decision Support Systems, 59. doi: 10.1016/j.dss.2013.11.001.

Kuzey, C., Uyar, A., \& Delen, D. (2014). The impact of multinationality on firm value: a comparative analysis of machine learning techniques. Decision Support Systems, 59. doi: 10.1016/j.dss.2013.11.001.

Lin, G. T., \& Tang, J. Y. H. (2009). Appraising intangible assets from the viewpoint of value drivers. Journal of Business Ethics, 88(4). doi: 10.1007/s 10551-008-9974-y.

Liu, Y. C., \& Yeh, I. C. (2016). Building valuation model of enterprise values for construction enterprise with quantile neural networks. Journal of Construction Engineering and Management, 142(2). doi: 10.1061/(ASCE)CO.1943-7862. 0001060.

Machová, V., \& Rowland, Z. (2018). Value generators of enterprises in the processing industry. In O. Dvouletý, M. Lukeš \& J. Mísař (Eds.). Proceedings of the $6^{\text {th }}$ international conference innovation management, entrepreneurship and sustainability. Prague: Oeconomica Publishing House.

Machová, V., \& Vrbka, J. (2018). Value generators for businesses in agriculture. In T. Löster \& T. Pavelka (Eds.). $12^{\text {th }}$ international days of statistics and economics. Slaný: Melandrum. 
Machová, V., \& Horák, J. (2020). Value generators in forestry and logging. In J. Horák, J. Vrbka, \& Z. Rowland (Eds.). SHS Web of conferences: innovative economic symposium 2019 - potential of Eurasian Economic Union. Les Ulis: SHS Web of Conferences. doi: 10.1051/shsconf/20207302003.

Miao, Q. (2010). Study on the financing difficulties of the rural SMEs and countermeasures. In R. J. Li, H. Zhang \& R. M. Zhao (Eds.). $4^{\text {th }}$ international conference on the development of small and medium-sized enterprises. Marrickville: Orient Academic Forum.

Miles, S. J., \& Van Clieaf, M. (2017). Strategic fit: key to growing enterprise value through organizational capital. Business Horizons, 60(1). doi: 10.1016/j.bushor .2016.08.008.

Neumaierová, I., \& Neumaier, I. (2008). Financial analysis of industry and construction for the year 2007. Analyzy MPO.

Olsen, M. D. (2008). Strategic management in the hospitality industry. New York: John Wiley \& Sons.

Panaretou, A. (2013). Corporate risk management and firm value: evidence from the UK market. European Journal of Finance, 20(12). doi: 10.1080/1351847X. 2013.766625.

Panaretou, A. (2014). Corporate risk management and firm value: evidence from the UK market. European Journal of Finance, 20(12). doi: 10.1080/1351847X. 2013.766625.

Rappaport, A. (1998). Creating shareholder value: a guide for managers and investors. New York: The Free Press.

Reno, A., \& Vadi, M. (2010). What factors predict the values of an organization and how? Tartu: The University of Tartu FEBA.

Scarlett, R. C. (2001). Value-based management. London: Ivey Management Services.

Serefoglu, C., \& Gokkaya, E. (2017). Challenges of rural SMEs in Ankara, Turkey. In C. A. Brebbia, J. Longhurst, E. Marco \& C. Booth (Eds.). $9^{\text {th }}$ international conference on sustainable development and planning - sustainable development and planning IX. Southampton: WIT Press. doi: 10.2495/SDP170271.

Stehel, V., \& Vochozka, M. (2016). The analysis of the economical value added in transport. Nase More, 63(3). doi: 10.17818/NM/2016/SI20.

Stehel, V., Horák, J., \& Vochozka, M. (2019). Prediction of institutional sector development and analysis of enterprises active in agriculture. $E \&$ M Ekonomie a Management, 22(4). doi:10.15240/tul/001/2019-4-007.

Strielkowski, W., Lisin, E., \& Herget, J. (2015). Success factors of rural SMEs: a case study of Polish micro enterprises. In E. Pastuszková, Z. Crhová, J. Vychytilová, B. Vytvrhlíková \& A. Knápková (Eds.). International scientific conference on finance and performance of firms in science, education and practice. Zlín: Tomas Bata University. 
Sulistyowati, L., Pardian, P., Syamsyiah, N., \& Deliana, Y. (2018). Development of small and medium business (SMES) of mango dodol processing to increase the added value (a case study in Ujungjaya Village, Indramayu District, West Java). In IOP conference series: earth and environmental science. Bristol: IOP Publishing. doi: 10.1088/1755-1315/142/1/012042.

Vidgen, R., Shaw, S., \& Grant, D. B. (2017). Management challenges in creating value from business analytics. European Journal of Operational Research, 261(2). doi: 10.1016/j.ejor.2017.02.023.

Vochozka, M., \& Machová, V. (2018). Determination of value drivers for transport companies in the Czech Republic. Naše More, 65(4). doi: 10.17818/NM/2018/ 4SI.6.

Vochozka, M., \& Rowland, Z. (2015). The evaluation and prediction of the viability of construction enterprises. Littera Scripta, $8(1)$.

Vochozka, M., \& Machová, V. (2017). Enterprise value generators in the building industry. In J. Váchal, M. Vochozka \& J. Horák (Eds.). SHS web of conferences: innovative economic symposium 2017 - strategic partnership in international trade. Les Ulis: SHS Web of Conferences.

Vochozka, M., Horák, J., \& Šuleř, P. (2019). Equalizing seasonal time series using artificial neural networks in predicting the Euro-Yuan exchange rate. Journal of Risk and Financial Management, 12(2). doi: 10.3390/jrfm12020076.

Wilimowska, Z., \& Krzysztoszek, T. (2013). The use of artificial neural networks in company valuation process. Studies in Computational Intelligence, 457. doi: 10.1007/978-3-642-34300-1_27. 


\section{Annex}

Table 1. Overview of active networks (value drivers)

\begin{tabular}{|c|c|c|c|c|c|}
\hline \multirow{2}{*}{ Statistics } & \multicolumn{5}{|c|}{ Network } \\
\hline & MLP 6-10-1 & MLP 6-8-1 & MLP 6-4-1 & MLP 6-10-1 & MLP 6-6-1 \\
\hline $\begin{array}{l}\text { Training } \\
\text { perform. }\end{array}$ & 0.554286 & 0.560275 & 0.522758 & 0.513835 & 0.57301 \\
\hline $\begin{array}{l}\text { Testing } \\
\text { perform. }\end{array}$ & 0.302619 & 0.399666 & 0.356501 & 0.362883 & 0.38089 \\
\hline $\begin{array}{l}\text { Validation } \\
\text { perform. }\end{array}$ & 0.444009 & 0.440621 & 0.457103 & 0.447603 & 0.452028 \\
\hline Training error & 284492002 & 282033996 & 298412060 & 302318885 & 275783357 \\
\hline Testing error & 305580778 & 281408284 & 292169990 & 290697617 & 286465671 \\
\hline $\begin{array}{l}\text { Validation } \\
\text { error }\end{array}$ & 168203420 & 168076256 & 164808540 & 166504593 & 166744171 \\
\hline $\begin{array}{l}\text { Training } \\
\text { algorithm }\end{array}$ & $\begin{array}{c}\text { BFGS } 84 \\
\text { (Quasi-Newton) }\end{array}$ & $\begin{array}{c}\text { BFGS } 83 \\
\text { (Quasi-Newton) }\end{array}$ & $\begin{array}{c}\text { BFGS } 68 \\
\text { (Quasi-Newton) }\end{array}$ & $\begin{array}{c}\text { BFGS } 113 \\
\text { (Quasi-Newton) }\end{array}$ & $\begin{array}{c}\text { BFGS } 92 \\
\text { (Quasi-Newton) }\end{array}$ \\
\hline $\begin{array}{l}\text { Error } \\
\text { function }\end{array}$ & Sum of squares & Sum of squares & Sum of squares & Sum of squares & Sum of squares \\
\hline $\begin{array}{l}\text { Activation of } \\
\text { hidden layer }\end{array}$ & Tanh & Logistic & Logistic & Exponential & Tanh \\
\hline $\begin{array}{l}\text { Output act. } \\
\text { function }\end{array}$ & Logistic & Logistic & Identity & Sine & Logistic \\
\hline
\end{tabular}

Table 2. Sensitivity analysis (value drivers)

\begin{tabular}{lcccccc}
\hline Retained NN & $\begin{array}{c}\text { Personnel } \\
\text { costs }\end{array}$ & Services & $\begin{array}{c}\text { Costs of } \\
\text { goods sold }\end{array}$ & $\begin{array}{c}\text { Interest } \\
\text { payable }\end{array}$ & $\begin{array}{c}\text { Materials and energy } \\
\text { consumption }\end{array}$ & \\
& & & & & \\
\hline 1.MLP 6-10-1 & 1.198500 & 1.165905 & 1.206182 & 1.138197 & 1.073037 & 0.999933 \\
2.MLP 6-8-1 & 1.275015 & 1.147395 & 1.165419 & 1.140442 & 1.064320 & 0.999995 \\
3.MLP 6-4-1 & 1.571311 & 1.051746 & 1.094362 & 1.138972 & 1.048445 & 1.000017 \\
4.MLP 6-10-1 & 1.113184 & 1.388282 & 1.076069 & 1.127949 & 1.104020 & 0.999968 \\
5.MLP 6-6-1 & 1.617142 & 1.255236 & 1.206398 & 1.141928 & 1.089871 & 0.999985 \\
Average & 1.355030 & 1.201713 & 1.149686 & 1.137498 & 1.075938 & 0.999980 \\
\hline
\end{tabular}


Table 3. Overview of active networks (value drivers, company location)

\begin{tabular}{|c|c|c|c|c|c|}
\hline \multirow{2}{*}{ Statistics } & \multicolumn{5}{|c|}{ Retained NN } \\
\hline & MLP 19-11-1 & MLP 19-9-1 & MLP 19-12-1 & MLP 19-4-1 & MLP 19-11-1 \\
\hline $\begin{array}{l}\text { Training } \\
\text { perform. }\end{array}$ & 0.454344 & 0.450429 & 0.532906 & 0.448903 & 0.461051 \\
\hline $\begin{array}{l}\text { Testing } \\
\text { perform. }\end{array}$ & 0.267149 & 0.262923 & 0.320189 & 0.278405 & 0.288838 \\
\hline $\begin{array}{l}\text { Validation } \\
\text { perform. }\end{array}$ & 0.406071 & 0.401747 & 0.407745 & 0.397044 & 0.409453 \\
\hline $\begin{array}{l}\text { Training } \\
\text { error }\end{array}$ & 326102527 & 327317147 & 294010096 & 328160906 & 323575104 \\
\hline $\begin{array}{l}\text { Testing } \\
\text { error }\end{array}$ & 312542518 & 313677788 & 301083462 & 309321339 & 307227762 \\
\hline $\begin{array}{l}\text { Validation } \\
\text { error }\end{array}$ & 174054743 & 174719963 & 173606200 & 176128249 & 173571801 \\
\hline $\begin{array}{l}\text { Training } \\
\text { algorithm }\end{array}$ & $\begin{array}{c}\text { BFGS 55 } \\
\text { (Quasi-Newton) }\end{array}$ & $\begin{array}{c}\text { BFGS 59 } \\
\text { (Quasi-Newton) }\end{array}$ & $\begin{array}{c}\text { BFGS } 93 \\
\text { (Quasi-Newton) }\end{array}$ & $\begin{array}{c}\text { BFGS } 61 \text { (Quasi- } \\
\text { Newton) }\end{array}$ & $\begin{array}{l}\text { BFGS } 64 \text { (Quasi- } \\
\text { Newton) }\end{array}$ \\
\hline $\begin{array}{l}\text { Error } \\
\text { function }\end{array}$ & Sum of squares & Sum of squares & Sum of squares & Sum of squares & Sum of squares \\
\hline $\begin{array}{l}\text { Activation } \\
\text { of hidden } \\
\text { layer }\end{array}$ & Tanh & Tanh & Logistic & Logistic & Logistic \\
\hline $\begin{array}{l}\text { Output } \\
\text { activation } \\
\text { function }\end{array}$ & Identity & Identity & Logistic & Identity & Identity \\
\hline
\end{tabular}

Table 4. Sensitivity analysis (value drivers, company location)

\begin{tabular}{llcccccc}
\hline Retained NN & $\begin{array}{c}\text { Interest } \\
\text { payable }\end{array}$ & $\begin{array}{c}\text { Personne } \\
\text { costs }\end{array}$ & $\begin{array}{c}\text { Costs of } \\
\text { goods } \\
\text { sold }\end{array}$ & Region & Services & $\begin{array}{c}\text { Materials and } \\
\text { energy } \\
\text { consumption }\end{array}$ & FA depreciation \\
\hline 1.MLP 19-11-1 & 1.103417 & 1.042815 & 1.035385 & 1.033781 & 1.011641 & 1.006369 & 1.000015 \\
2.MLP 19-9-1 & 1.104524 & 1.052259 & 1.039834 & 1.021578 & 1.016066 & 1.004283 & 0.999835 \\
3.MLP 19-12-1 & 1.118212 & 1.110001 & 1.098298 & 1.096568 & 1.058054 & 1.02902 & 1.000006 \\
4.MLP 19-4-1 & 1.095242 & 1.040446 & 1.032311 & 1.029114 & 1.01249 & 1.008236 & 1.000013 \\
5.MLP 19-11-1 & 1.115482 & 1.041858 & 1.034058 & 1.036744 & 1.01145 & 1.009521 & 1.000006 \\
Average & 1.107375 & 1.057476 & 1.047977 & 1.043557 & 1.02194 & 1.011486 & 0.999975 \\
\hline
\end{tabular}


Table 5. Comparison of most successful neural networks

\begin{tabular}{lcc}
\hline \multicolumn{1}{c}{ Network } & MLP 6-6-1 & MLP 19-12-1 \\
\hline Training performance & 0.57301 & 0.532906 \\
Testing performance & 0.38089 & 0.320189 \\
Validation performance & 0.452028 & 0.407745 \\
Training error & 275783357 & 294010096 \\
Testing error & 286465671 & 301083462 \\
Validation error & 166744171 & 173606200 \\
Training algorithm & BFGS 92 & BFGS 93 \\
Error function & (Quasi-Newton) & (Quasi-Newton) \\
Activation of hidden layer & Sum of squares & Sum of squares \\
Output activation function & Tanh & Logistic \\
\hline
\end{tabular}

Figure 1. Scatter plot illustrating actual EVA Equity and calculations using the most successful models

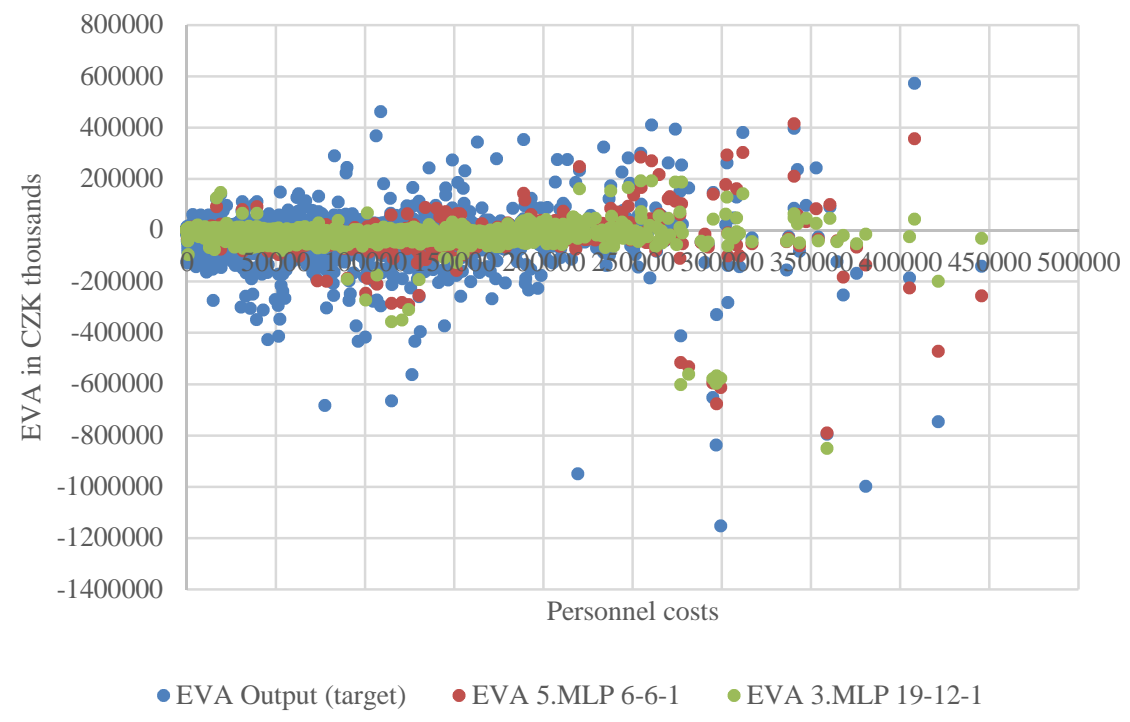

